It is activated by a 12 -volt battery giving 12 amperes current which creates a $4 \mathrm{lb}$. pull on the end of the magnet core.

No attempt is made to use statistics and the following quoted figures are merely interesting. During the last six months battle and accident casualties have been personally dealt with to the number of roughly 600 cases; of these approximately 300 were probable cases of intra-ocular foreign body and had radiological examination done resulting in 50 per cent. negative and 50 per cent. positive films. Of these latter 150 cases only 50 had successful operations for removal of the intra-ocular foreign body. Many eyes were lost for a variety of reasons, infection being negligible. Perhaps the commonest reason was that the particular eye was too badly damaged to survive without undue risk, another reason being that the foreign bodies were non-magnetic. Included were two cases of siderosis with loss of vision, each resulting from severat months retention of an iron foreign body, removed in either case. There was no evidence of sympathetic ophthalmia in either of these cases, nor has it been seen in any others.

In conclusion, the purpose of this paper is :

1. To recommend the equatorial ring method for radiological investigation and localisation of all orbital and ocular foreign bodies.

2. To plead for the more confident use of the smaller " hand" electro-magnet which, if properly designed, may with advantage. replace the giant magnet.

3. To convey some,impressions resulting from recent activity in a busy centre of ophthalmic war surgery.

\title{
HYSTERIA IN OPHTHALMOLOGY* Experiences with New Zealand Troops in the Middle East
}

BY

Howard Coverdale, Lieut.-Col. N.Z.M.C.

- THE writer was ophthalmologist at the New Zealand Hospital at Helwan, Egypt, for three years from the end of March, 1941. This hospital served New Zealand Base and to it were referred the great majority of New Zealand ophthalmic sick or wounded as direct admissions, as transfers for treatment or disposal, or as out-patients for investigation.

It may reasonably be assumed that, with the exception of any

* Received for publication, September 6, 1944. 
there may have been amongst the 4,139 lost as prisoners of war in Greece and Crete, the number given below represents almost all the cases of hysteria with ocular symptoms diagnosed from amongst the 58,927 troops which constituted the New Zealand Expeditionary Force to Middle East up to the end of November, 1943.

Only New Zealanders are included in this enquiry, although, at Helwan, during the period taken, about a third of the ophthalmic patients were from British Units. While the incidence seemed to be about the same, 'any comparison between the two groups would, for various reasons, have neither valưe nor interest.

The diagnosis of hysteria in ophthalmology is facilitated if the term is limited to those cases of psychoneurosis with an incapacitating loss of function, the intensity of other symptoms and signs being regarded as subsidiary. This has been the aim here, and, while it may seem presumptuous to tabulate and count cases of such an ill-defined disorder, yet, in practice, it is seldom difficult to decide, at least to one's own satisfaction, when the diagnosis should or should not be made. It is more difficult, in mild cases, to assess the future usefulness of the man as a soldier.

In Egypt; the demands on the ophthalmologist's energy. and time were always so great that, even had he the knowledge and psychiatric experience, he could do no more than make the diagnosis, give an emphatic reassurance and complete the formalities for disposal. No attempt, therefore, is made here to trespass into psychiatry, and any comments are made with diffidence.' It may be said, however, that, as in civil life, the average hysteric is an obsessed, humourless type of man, incapable of responding to explanation, reason or reassurance.

Up to the end of 1943 ; 95 cases were diagnosed, 50 of which were considered severe and 45 mild. The average age was 30 years.

Of the 95, 62 had not been in action with the Division. While the remaining 33 had been with the Division in the field, though not necessarily in action in the face of the enemy, very few had been sent back to Base because the disability had occurred during combat. The majority had paraded sick and been diagnosed soon after their arrival in Egypt.

The highest incidence occurred during and immediately after the Campaign in Greece and Crete when 32 cases were diagnosed, ' 24 from Base and 8 from the Division. Of those from Base, 15 had just arrived in Egypt. It is possible that colourful accounts of Germany's air superiority had some effect on the morale of the hysteria-prone in Egypt. Thereafter, there were only two periods when the incidence rose above negligible figures; during the second battle of Libya in October, November and December of 
1941 (17 cases) and during the intermittent but desperate actions from July to October of 1942 at Minqua Qain and on the El Alamein line (13 cases).

From or during the actions which followed the break-through at Alamein until the German capitulation in Tunisia six and a half months later, there were only 6 cases, 1 from the Division and 5 from Base, 3 of which 'were from reinforcements just arrived in Egypt.

The most interesting fact to emerge from the clinical examination of these men was that a high proportion had some pre-existing ocular defect dating, in most cases, from childhood.

Amongst the 95 cases, there were 44 with eyes defective at enlistment from squint, old injury, chronic disease, developmental defect or very high degree of refractive error, and 9 with histories of pre-enlistment head or eye injuries, but with no signs remaining.

It may be that such ocular disabilities tend to make men hysteria-prone or, alternatively, that, in those who are hysteriaprone from heredity, environment or other causes, the disability tends to appear in that organ which the man, consciously or unconsciously, believes to be weak.

Early in the war, many major ocular defects escaped the notice of the general practitioners who examined recruits in New Zeafand, but, from late in 1942 onwards, a number of mobile optical units with opticians in charge visited all camps in the country, equipped those requiring them with spectacles and referred to ophthalmologists those whose ocular state made it seem unlikely that they would give useful service abroad. Owing to the entry of Japan into the war, no reinforcements arrived in Egypt in 1942, but there is no doubt that, in 1943, this investigation did much to reduce the incidence of hysterical amblyopia.

The following tables give the number of cases in which certain volunteered symptoms were complained of and in which various . signs were encountered on examination.

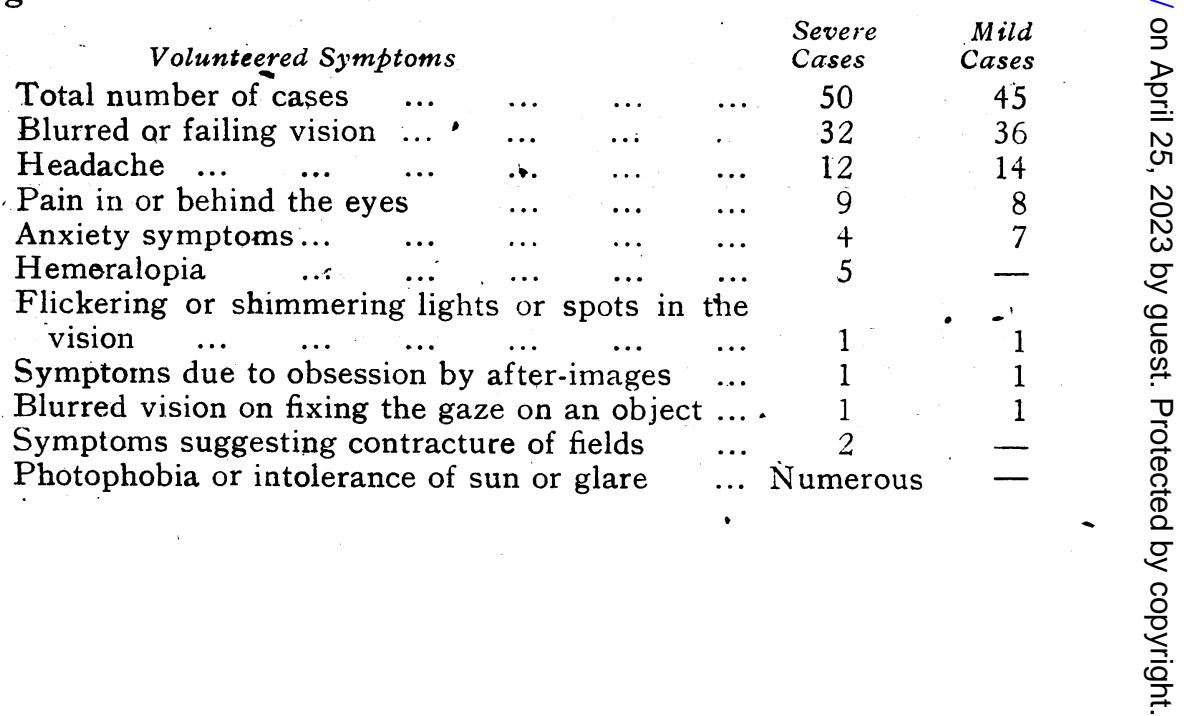


Signs on Examination

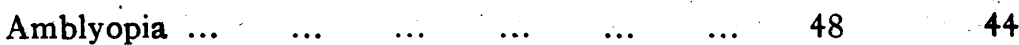

$\begin{array}{llllll}\text { Contracted fields of vision } & \ldots & \ldots & \ldots & 43 & 39\end{array}$

$\begin{array}{llllllll}\text { Blepharospasm } & \ldots & \ldots & \ldots & \ldots & \ldots & 14 & 7\end{array}$

$\begin{array}{lllllllll}\text { Signs of anxiety } & \ldots & \ldots & \ldots & \ldots & \ldots & 7 & -\end{array}$

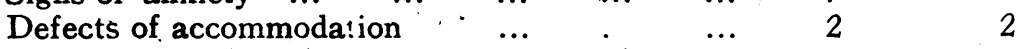

$\begin{array}{llllllll}\text { Spasmodic squint } & \ldots & \ldots & \ldots & \ldots & \ldots & 3 & -\end{array}$

Self-inflicted conjunctivitis (presumed) $(2$ Maoris

and 1 mental defective)... $\quad \ldots \quad \ldots \quad \ldots \quad$...

\section{Disposal}

Forty-two of the 50 severe cases were regraded at the Eye Department for repatriation to New Zealand, and the remaining 8 were regraded to Base. The 45 milder cases were referred back to their Units with reassurances. This difference in disposal was based on a personal opinion of each man's future usefulness as a soldier. Often, there were no reliable criteria for this, but, where there was evidence of pre-enlistment hysteria or where the eyes showed any such defect as congenital cataract or old perforating injury, the case was regarded as severe.

Fifty-three men remained on active service, and the following particulars of their histories, subsequent to their return to their units, have been supplied by Captain G. E. Vercoe, officer in charge of Advanced 2 Echelon, 2 N.Z.E.F.

Repatriated to N.Z. on furlough after serving for about 3 years overseas ... $\quad \ldots \quad \ldots$

Regraded at the Eye Department to Base and still on active service on May 31, $1944 \quad \ldots$

Regraded subsequently elsewhere :-

(1) For repatriation to N.Z.

(a) For psychoneurosis... $\quad \ldots \quad \ldots \quad 11$

$\begin{array}{ccccccc}\text { (2) To Base } & \ldots & \ldots & \ldots & \ldots & \ldots & 9 \\ \end{array}$

Number of Men

5

Not regraded :-

(a) Still with Divisional Units on May 31 ,

(b) $\begin{array}{llllll}19+4 & \ldots & \ldots & \ldots & \ldots & \ldots\end{array}$

Repatriated to N..$\ddot{Z}$. without Medical Boarding

Killed in action ... $\quad \ldots \quad \ldots \quad \ldots$

Died (septicaemia)
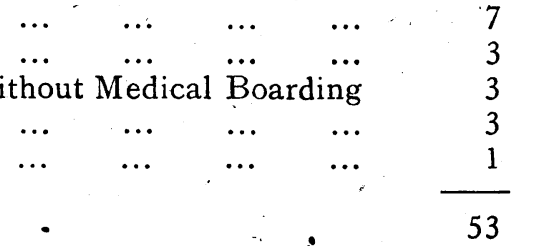

In those cases where, after the diagnosis of hysteria had been made, the men were returned to their units and were subsequently regraded elsewhere for repatriation to New Zealand on account 
Note:-For permission to publish this paper I wish to thank Brigadier S. Kenrick, C.B.E., D.M.S., 2, N.Z.E.F. 